\title{
NON-RANDOMISED CONTROL TRIAL OF GLYCOLIC ACID 12\% CREAM VERSUS AZELAIC ACID 10\% CREAM IN MELASMA
}

Fatima Razvi' ${ }^{1}$ Nayeem Sadath Haneef², Polishetty Sravanthi' ${ }^{3}$ Fatima Ummul Hasnath ${ }^{4}$, Ramesh Bang 5

${ }_{1}^{1}$ Associate Professor, Department of Dermatology, Venereology and Leprosy, Deccan College of Medical Sciences, Hyderabad. 2Professor and HOD, Department of Dermatology, Venereology and Leprosy, Deccan College of Medical Sciences, Hyderabad. 3Junior Resident, Department of Dermatology, Venereology and Leprosy, Deccan College of Medical Sciences, Hyderabad. 4Senior Resident, Department of Dermatology, Venereology and Leprosy, Deccan College of Medical Sciences, Hyderabad. ${ }_{5}^{5}$ Senior Resident, Department of Dermatology, Venereology and Leprosy, Deccan College of Medical Sciences, Hyderabad.

ABSTRACT
BACKGROUND
Melasma is most common acquired hypermelanosis which presents with asymmetrical hyperpigmentation usually involving the
malar, mandibular or centrofacial area. It is seen in South East Asia especially in skin photo types 3 \& 4 . It is seen mainly in women
during childbearing age and its onset may correlate with pregnancy or the use of oral contraceptive pills. The other commonly
known factors in its pathogenesis include genetic influences, endocrine factors, use of cosmetics, certain drugs like anticonvulsants,
steroids and exposure to sunlight (UVA, UVB and visible light). Hydroquinone is being used for treatment of melasma since long
time as it is efficacious, but it has adverse effects like contact dermatitis, exogenous ochronosis. Hence, we tried non-hydroquinone
based topical medications which are safe, efficacious and are known to target melanocytes and various steps of melanogenesis.
The aim of this study is to compare the efficacy of topical Glycolic acid $12 \%$ cream versus Azelaic acid $10 \%$ cream in melasma.

\section{MATERIALS AND METHODS}

Settings and Design- Prospective non-randomised controlled trial of efficacy and safety of Glycolic acid $12 \%$ cream versus Azelaic acid $10 \%$ cream.

100 patients of melasma who completed all followups were included in this study for a period of 12 weeks and randomly assigned to one of the following groups:

Group A - 12\% Glycolic acid cream.

Group B - 10\% Azelaic acid cream.

Statistical Analysis- Every 2 weeks and at the end of 12 weeks, the two treatment groups were compared for efficacy and adverse effects and the results were analysed with Chi-square test. Yates correction was applied wherever necessary.

\section{RESULTS}

The response to Azelaic acid 10\% cream was relatively higher than Glycolic acid $12 \%$ cream. Cut-offs were considered and these differences were statistically significant (0.001 and 0.012). It was observed that higher proportion of patients with Glycolic acid $12 \%$ cream had adverse effects when compared to Azelaic acid $10 \%$ cream except for dryness.

\section{CONCLUSION}

When the two topical medications were compared we found that Azelaic acid $10 \%$ cream was more tolerable and efficacious with maximum resolution than Glycolic acid $12 \%$ cream.

\section{KEYWORDS}

Glycolic Acid, Azelaic Acid, Melasma.

HOW TO CITE THIS ARTICLE: Razvi F, Haneef NS, Sravanthi P, et al. Non-randomised control trial of glycolic acid $12 \%$ cream versus azelaic acid 10\% cream in melasma. J. Evolution Med. Dent. Sci. 2017;6(94):6891-6894, DOI: 10.14260/jemds/2017/1493

\section{BACKGROUND}

Melasma is a very common pigmentary cutaneous disorder accounting for 2-4\% of dermatology clinics in South East Asia. The increased incidence of melasma in these regions could be due to intense UV light exposure and increased response of melanocytes in dark races to UV radiation. In India, it is the most common pigmentary disorder with an incidence of approximately $10 \% .{ }^{1}$ Melasma occurs more common in

'Financial or Other Competing Interest': None.

Submission 14-09-2017, Peer Review 25-11-2017,

Acceptance 01-12-2017, Published 18-12-2017.

Corresponding Author:

Dr. Nayeem Sadath Haneef,

3/102, Kalyani, Sahara States,

Mansoorabad, LB Nagar,

Hyderabad - 500068.

E-mail: dr_nayeemsadath@yahoo.co.in

DOI: $10.14260 /$ jemds $/ 2017 / 1493$ females especially during childbearing age, which probably could be because of hormonal influence. In many cases onset of disease is after pregnancy or after use of oral contraceptive pills. ${ }^{2}$

Melasma is also called as chloasma and mask of pregnancy. ${ }^{3}$ However, few other factors are thought to be responsible for its pathogenesis like genetic factors, endocrinological causes and cosmetics, phototoxic and drugs such as anticonvulsants. ${ }^{4}$

Of these, family history and sun exposure are the most important causes associated with melasma in large number of patients. Dermal factors also play a very important role. Dermal fibroblast expression of stem cell factors and the receptor c-kit in melanocytes are significantly increased in lesional skin in melasma, they also help in melanocyte survival. It is postulated that ultraviolet light stimulates fibroblast activity and melanogenesis via stem cell factor and C-kit activation. 5 Recently, histopathological studies have 
shown increased vascularisation within melasma lesions as compared to the surrounding normal skin. ${ }^{6}$

According to the Distribution of Lesions, Three Clinical Patterns of Melasma are Recognised. ${ }^{7}$

1. The "centrofacial pattern."

2. The "malar pattern."

3. The "mandibular pattern."

Though centrofacial pattern is most common in females, in Indian males, malar pattern was found more common. ${ }^{8}$ Histologically and dermoscopically melasma can be classified as (1) Brown Hypermelanosis (2) Blue Hypermelanosis (3) Mixed Hypermelanosis. Mixed hypermelanosis is due to increased epidermal and dermal pigmentation.9,10 The severity of darkening increases with age. Significant Marionette line pigmentation in $38 \%$ of women, nasal pigmentation (transverse nasal groove) in $42 \%$ of women were noted. ${ }^{11,12}$

The treatment is challenging and prolonged and requires wide approaches in Asian Races. Hydroquinones were earlier efficacious also but have significant side effects like contact dermatitis, exogenous ochronosis. Non-hydroquinones based treatments are more preferred nowadays as these agents are natural, safe and proved to be efficacious in melasma. They target the melanosis and inhibit melanogenesis. Various nonhydroquinone lightening agents belong to 4 groups: tyrosinase inhibitors, inhibiting melanosome transfer, increasing turnover of epidermis, antioxidant effect.

Various treatment modalities which have been found to be efficacious in treatment of melasma patients are as follows ${ }^{13}$ :

\section{Randomised - Controlled Trials}

- $4 \%$ Hydroquinone.

- $4 \%$ Hydroquinone $+0.05 \%$ retinoic acid $+0.01 \%$ fluocinolone acetonide.

- $4 \%$ Hydroquinone $+10 \%$ glycolic acid.

- $0.1 \%$ Tretinoin.

- $\quad 0.05 \%$ Retinoic acid.

2. Controlled Trials without Randomisation

- $70 \%$ Glycolic acid.

- Jessner's solution (14\% lactic acid, $14 \%$ salicylic acid, $14 \%$ resorcinol).

3. Case Control or Cohort Studies

- $4 \%$ Hydroquinone $+5 \%$ Glycolic acid.

- $\quad 4 \%$ Kojic acid $+5 \%$ Glycolic acid.

4. Case Reports

- $20-30 \%$ Salicylic acid.

- $1-5 \%$ Retinoic acid.

Azelaic acid is a competitive inhibitor of tyrosinase, and glycolic acid is an alpha hydroxy acid which is known to accelerate epidermal turnover and causes desquamation thereby inducing lightening of lesions.

We have tried to compare efficacy and adverse effects of two relatively safe non-irritant therapeutic modalities in melasma in this comparative study.

\section{MATERIALS AND METHODS}

Study design: Prospective nonrandomised control trial was conducted to compare efficacy of Glycolic acid 12\% versus Azelaic acid $10 \%$ in melasma.
Sample size and sampling and allocation: Convenient sampling was used with all patients reporting to the OPD during the study period included in the study and screened for inclusion and exclusion criteria. During the study period, 140 female patients of age between 20-40 years reported, out of which 40 dropped out before the data could be compiled. Hence, a total of 100 patients were included of which 50 were allocated to Group A and 50 into Group B alternatively.

\section{Patient Selection Criteria}

\section{Inclusion Criteria}

1. Females.

2. Age between 20-40 years.

3. Patients who were not on any topical medications for a period of 2 weeks.

\section{Exclusion Criteria}

1. Patients who didn't turn up for followup for a given period of time.

2. Pregnant and lactating women.

\section{Therapeutic Groups}

Group A- 12\% Glycolic acid.

Group B- 10\% Azelaic acid.

\section{Study Period}

12 weeks.

Statistical methods used: The data thus collected was entered into MS Excel and analysed. Frequency distribution tables were put up. Proportions were compared in the two groups by using Chi-square test. Yates correction was applied wherever necessary.

\section{Method of Treatment}

Both the topical medications were applied overnight followed by wash off in the morning after 6-8 hours. Patients were advised to use a sunscreen of $30 \mathrm{SPF}$ in the daytime. Treatment was continued for 12 weeks and improvement was assessed at the end of every 2 weeks.

\section{Grading of Severity by Modified MASI Score ${ }^{14}$ :}

\begin{tabular}{|l|c|}
\hline 0 & Absent \\
\hline 1 & $<10 \%$ \\
\hline 2 & $10-29 \%$ \\
\hline 3 & $30-49 \%$ \\
\hline 4 & $50-69 \%$ \\
\hline 5 & $70-89 \%$ \\
\hline 6 & $90-100 \%$ \\
\hline \multicolumn{2}{|c|}{ Area of Involvement $(\boldsymbol{A})$} \\
\hline
\end{tabular}

\begin{tabular}{|l|c|}
\hline 0 & Absent \\
\hline 1 & Small \\
\hline 2 & Moderate \\
\hline 3 & Marked \\
\hline 4 & Severe \\
\hline \multicolumn{2}{|c|}{ Darkness (D) } \\
\hline
\end{tabular}

Area of involvement and Darkness are sufficient for measuring severity. Score ranges from 0-24. 


\section{RESULTS}

2 groups of 50 patients each received Glycolic acid 12\% and azelaic acid $10 \%$. All patients completed the study. Baseline parameters of all patients were similar in terms of modified MASI score.

\section{No. of patients showing response to Glycolic acid:}

\begin{tabular}{|c|c|c|c|c|c|}
\hline Response & $\begin{array}{c}\text { No } \\
\text { Response }\end{array}$ & $\mathbf{1 - 2 5 \%}$ & $\mathbf{2 6 - 5 0 \%}$ & $\mathbf{5 1 - 7 5 \%}$ & $\mathbf{7 6 - 1 0 0 \%}$ \\
\hline $\begin{array}{c}\text { No. of } \\
\text { Patients }\end{array}$ & - & 15 & 20 & 10 & 5 \\
\hline
\end{tabular}

Table 1. Glycolic acid 12\% cream Response

No. of patients showing response to Azelaic acid:

\begin{tabular}{|c|c|c|c|c|c|}
\hline Response & $\begin{array}{c}\text { No } \\
\text { Response }\end{array}$ & $1-25 \%$ & $26-50 \%$ & $51-75 \%$ & $76-100 \%$ \\
\hline $\begin{array}{c}\text { No. of } \\
\text { patients }\end{array}$ & - & - & 15 & 20 & 15 \\
\hline \multicolumn{6}{|c|}{ Table 2. Azelaic acid 10\% cream response } \\
\hline
\end{tabular}

Chi-square test was performed to determine the significance of differences. Yates correction was applied wherever necessary.

\begin{tabular}{|c|c|c|c|c|}
\hline Response & $\begin{array}{c}\text { Glycolic } \\
\text { Acid 12\% }\end{array}$ & $\begin{array}{c}\text { Azelaic } \\
\text { Acid 10\% }\end{array}$ & $\chi^{\mathbf{2}}$ & P value \\
\hline$>50 \%$ & 15 & 35 & 16.00 & 0.001 \\
\hline$>75 \%$ & 5 & 15 & 6.25 & 0.012 \\
\hline \multicolumn{5}{|c|}{ Table 3. Response to Treatment } \\
\hline
\end{tabular}

The response to azelaic acid was relatively higher if $50 \%$ or $75 \%$ cut-offs were considered and these differences were statistically significant (0.001 and 0.012$)$.

\begin{tabular}{|c|c|c|c|c|}
\hline $\begin{array}{c}\text { Side } \\
\text { Effects }\end{array}$ & $\begin{array}{c}\text { Glycolic } \\
\text { Acid 12\% }\end{array}$ & $\begin{array}{c}\text { Azelaic } \\
\text { Acid 10\% }\end{array}$ & $\boldsymbol{\chi}^{\mathbf{2}}$ & P value \\
\hline Pruritus & 16 & 03 & 10.98 & 0.001 \\
\hline Burning & 26 & 07 & 16.33 & 0.000 \\
\hline Erythema & 12 & 03 & 6.35 & 0.012 \\
\hline Wrinkles & 11 & 02 & 7.16 & 0.007 \\
\hline Dryness & 09 & 04 & 2.21 & 0.137 \\
\hline
\end{tabular}

Table 4. Adverse effects of Azelaic acid and Glycolic acid

It was observed that higher proportion of patients with glycolic acid had side effects when compared to azelaic acid group except for dryness. The differences in proportions of patients suffering pruritus, burning, erythema and dryness were statistically significant.

\section{DISCUSSION}

Melasma is one of the most common hyperpigmentary disorder, a frustrating condition. Relapse is invariable despite optimum preventive measures and dermatologists can only ensure "treatment and maintenance" rather than permanent cure. Despite continuous quest for the aetiological and factors and pathogenic mechanisms contributing to melasma, its pathophysiology remains elusive and treatment is challenging.

The major aetiological factors implicated in melasma seem to act in concert. In a recent global survey, the incidence of different causative factors was $100 \%$ for sunlight exposure, $27 \%$ for pregnancy, $14 \%$ for cosmetics, $13 \%$ for familial factors, $6.3 \%$ for OCP use. Various other factors like thyroid disorders, drugs (phototoxic and photoallergic), cosmetics, infection and Chlamydia Trachomatis, stress, melanocytic and lentiginous nevi are also listed; however, the evidence supporting their definitive role is weak.

The treatment is challenging, prolonged and requires a judicious approach especially in dark skinned patients. Hydroquinone although quite efficacious, may have significant side effects including skin irritation, contact dermatitis and exogenous ochronosis. Hence, there is growing need for alternative natural, safe and efficacious skin lightening agents. Recent studies show that several nonhydroquinone agents may also play an important role in therapy for pigmentation. 15 These agents selectively target hyperplastic melanocytes and inhibit key regulation steps in melanogenesis.

In our study, patients benefitted by both nonhydroquinone agents i.e. azelaic acid (10\%) and glycolic acid (12\%). With glycolic acid most people (20 people i.e., $40 \%$ ) showed resolution of around $26 \%-50 \%$ and $76-100 \%$ was seen in around $10 \%$ of people ( 5 people) whereas with azelaic acid most people (20 people i.e. $40 \%$ ) showed around $51-75 \%$ resolution, and maximum resolution i.e. $76-100 \%$ was seen in around $30 \%$ of patients. A study by Farshi S suggests that $20 \%$ azelaic acid cream applied twice daily may be more effective than hydroquinone $4 \%$ in reducing mild melasma. ${ }^{16}$ Our results are in congruence with Farshi study showing good efficacy of azelaic acid 10\% cream.

While comparing side effects of both azelaic and glycolic acid most common side effect was burning sensation in 26 patients of glycolic acid and 7 patients of azelaic acid. Pruritus is next common side effect in 6 patients of glycolic acid users and 3 patients of azelaic acid users. The condition is same with other side effects like erythema and dryness where glycolic acid users affected more than Azelaic acid users.

By the above observations we can infer that side effects were more common due to Glycolic acid when compared to Azelaic acid. This shows that Azelaic acid ( $p$ value 0.001 ) is better than glycolic acid in terms of higher efficacy as well as lesser adverse effects.

\section{CONCLUSION}

The present study on topical therapy of melasma comparing two non-hydroquinone agents namely azelaic acid $10 \%$ cream and glycolic acid $12 \%$ cream concludes that azelaic acid was more efficacious, tolerable and safe than glycolic acid.

\section{REFERENCES}

[1] Pasricha JS, Khaitan BK, Dash S. Pigmentary disorders in India. Dermatol Clin 2007;25(3):343-52.

[2] Ortonne JP, Arellano L, Berneburg M, et al. A global survey of the role of ultraviolet radiation and hormonal influences in the development of melasma. J Eur Acad Dermatol Venereol 2009;23(11):1254-62.

[3] Grimes PE. Melasma: etiological and therapeutic considerations. Arch Dermatol 1995;131(12):1453-7.

[4] Katsambas A, Antonio C. Melasma. Classification and treatment. J Eur Head Dermatol Venereol 1995;4(3):217-23 
[5] Kang HY. Etiopathogenesis of melasma. In: Lahiri K, Chatterjee M, Sarkar R. eds. Pigmentary disorders: a comprehensive compendium. New Delhi: Jaypee Brothers 2014:282-6.

[6] Kim EH, Kim YE, Lee ES, et al. The vascular characteristics of melasma. J Dermatol Sci 2007;46(2):111-6.

[7] Mosher DB, Fitzpatrick TB, Ortonne JP. Hypomelanoses and hypermelanoses. In: Freedburg IM, Eisen AZ, Woeff K. eds. Dermatology in general medicine. $5^{\text {th }}$ edn. New York: McGraw-Hill 1999:9451016.

[8] Sarkar R, Puri P, Jain RK, et al. Melasma in men: a clinical, aetiological and histological study. J Eur Acad Dermatol Venereol 2010;24(7):768-72.

[9] Ashton R, Heppard B, Cooper H. Differential diagnosis in dermatology. London: Radcliffe Publishing Ltd., 2014:288-300.

[10] Singh G. Non-melasma facial melanoses. In: Lahiri K, Chatterjee M, Sarkar R. eds. Pigmentary disorders: a comprehensive compendium. New Delhi: Jaypee Brothers 2014:390-402.
[11] Khanna N, Rasool S. Facial melanoses: Indian perspective. Indian J Dermatol Venereal Leprol 2011;77(5):552-64.

[12] Vashi NA, Kundu RV. Facial hyperpigmentation: causes and treatment. Br J Dermatol 2013;169(Suppl 3):4156.

[13] Kodali S, Guevara IL, Carrigan CR, et al. A prospective, randomized, split-face, controlled trial of salicylic acid peels in the treatment of melasma in Latin American women. J Am Acad Dermatol 2010;63(6):1030-5.

[14] Pandya AG, Hynan LS, Bhore R, et al. Reliability assessment and validation of the Melasma Area and Severity Index(MASI) and a new modified MASI scoring method. J Am Acad Dermatol 2011;64(1):7883, 83.e1-2.

[15] Sarkar R, Arora P, Garg KV. Cosmeceuticals for hyperpigmentation: What is available? J Cutan Aesthet Surg 2013;6(1):4-11.

[16] Farshi S. Comparative study of therapeutic effects of $20 \%$ Azelaic acid and hydroquinone $4 \%$ cream in the treatment of melasma. J Cosmet Dermatol 2011;10(4):282-7. 